\title{
Commentary: Intraventricular conduit repair for double-outlet right ventricle with noncommitted ventricular septal defect-How bright is the light at the end of the tunnel?
}

\author{
James Jaggers, MD, and Matthew Stone, MD, $\mathrm{PhD}$
}

From the Childrens Hospital Colorado, University of Colorado Anschutz Campus, Aurora, Colo.

Disclosures: Authors have nothing to disclose with regard to commercial support.

Received for publication Aug 4, 2019; accepted for publication Aug 5, 2019; available ahead of print Oct 24, 2019.

Address for reprints: James Jaggers, MD, Department of Surgery, Barton Elliman Chair of Pediatric Cardiac Surgery, Childrens Hospital Colorado, University of Colorado, 13123 E 16th Ave, B200, Aurora, CO 80045 (E-mail: James.Jaggers@ childrenscolorado.org).

J Thorac Cardiovasc Surg 2020;159:2404-5

$0022-5223 / \$ 36.00$

Copyright (c) 2019 by The American Association for Thoracic Surgery

https://doi.org/10.1016/j.jtcvs.2019.08.052

Biventricular repair for patients with double-outlet right ventricle (DORV) and noncommitted ventricular septal defect (VSD) requires complex surgical decision making and remains one of the more technically difficult operations. This subtype of DORV is characterized by the presence of a double infundibulum. The aortic outflow tract is separated from the pulmonary by a conal septum that does not contribute to the ventricular septation. It is generally accepted that both great vessels arise $100 \%$ from the right ventricle and that the VSD is located a distance greater than the aortic diameter from both arterial valves. ${ }^{1}$ The direction of the flow through the VSD is perpendicular into the cavity of the right ventricle, not directed toward either outflow tract. Other important morphologic details in patients with DORV with noncommitted VSD include the distance between the VSD and the great arteries, the location of the VSD (inlet, muscular, or central perimembranous), atrioventricular valves and chordal apparatus, the coronary artery pattern, and cardiac situs.

In their study in this issue of the Journal, Lu and colleagues $^{2}$ report the use of an intraventricular polytetrafluoroethylene conduit from the VSD to the aorta in 31 patients (age range, 2-23 years; median, 5.4 years) with DORV and noncommitted VSD. This technique potentially simplifies the repair. According to the experience of Lu and colleagues, ${ }^{2}$ a $16-\mathrm{mm}$ polytetrafluoroethylene graft can be placed in children younger than 5 years, whereas a 19-mm graft is easily placed in patients older than 5 years.

The outcomes for this study were excellent, with no perioperative mortality and $93 \%$ survival during a 93-month median follow-up duration. Only 1 patient had significant left ventricular outflow tract obstruction (LVOTO) in the conduit.

The technique described has several potential advantages. First, it avoids significant manipulation of the

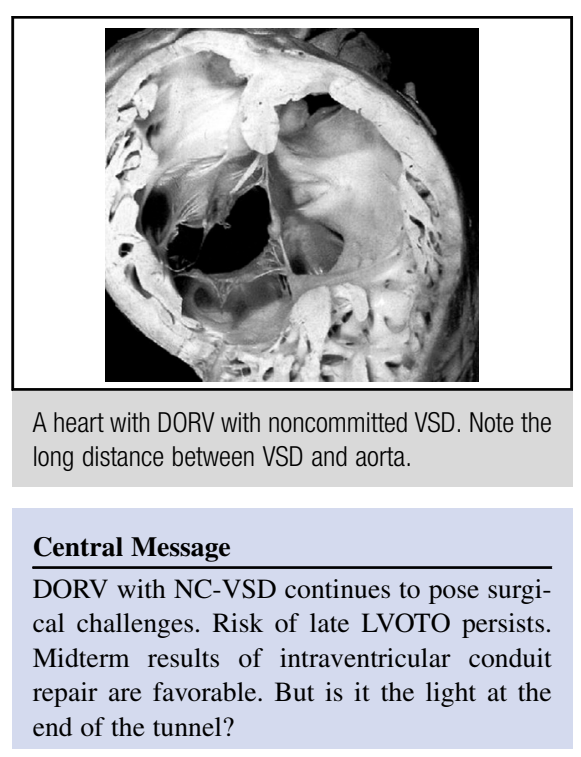

See Article page 2397.

tricuspid valve chords. Only 4 patients required tricuspid valve chord reimplantation, and only 4 patients had greater than mild tricuspid valve insufficiency. Lu and colleagues ${ }^{2}$ carefully describe the intraventricular route that the conduit should take, as determined by the position of the aorta. If the aorta is anterior and right of the pulmonary artery, the conduit should pass posterior or below the papillary muscle of the conus. If the aorta is positioned anterior and left of the pulmonary artery, then the conduit should be placed anterior or above the conal papillary muscle. This careful positioning likely results in less distortion of the tricuspid subvalvular apparatus.

Second, it results in a shorter distance of prosthetic, nonmuscular, akinetic pathway from the VSD to the aorta. With the intraventricular baffle or tunnel type repair, late LVOTO can occur in approximately $10 \%$ to $30 \%$ of patients, and the length of tunneled pathway has been correlated with the development of late LVOTO. ${ }^{3,4}$ The most common cause of late LVOTO is bulging or encroachment of the underlying septal or subaortic conal muscle. Other sites of stenosis can be at the VSD-baffle junction or at the aortic valve annulus. With the conduit repair, the conal muscle may be less likely to encroach or 
compress the conduit. As long as the VSD is large, or is enlarged surgically to a diameter greater than the aortic annulus, stenosis is unlikely to occur at the VSD. This leaves only the diameter of the conduit as the limiting factor.

Third, some have recommended baffling the VSD to the pulmonary artery and performing an arterial switch procedure. ${ }^{1}$ The arterial switch procedure, however, cannot be used in a patient with significant pulmonary valvar stenosis, which many of these patients have. The intraventricular conduit technique avoids the necessary translocation of the coronary arteries, which are often abnormal. It also avoids the LeCompte maneuver, which can be tricky in patients with more side-by-side great vessels.

It is important to note that the age (range, 2-23 years; median, 5 years) of the patients in this conduit series is significantly older than in contemporary series that used either an interventricular baffle or arterial switch operation with VSD baffle to the pulmonary artery, in which mean ages were less than a year. This is, of course the Achilles heel of this technique. Placement of a small conduit in smaller patients will undoubtedly result in their outgrowing the conduit very early, necessitating obligate reoperation, likely before adolescence. Because of this limitation, a potential strategy might be to palliate a child's condition until such an age and size have been reached that a large conduit might be possible. Although this may be a valid strategy, the risks of prolonged and possibly multiple palliative procedures, as well as the palliation physiology, must be considered, and the potential benefits of an intraventricular conduit likely do not outweigh the risks.

On the basis of the results of the study of $\mathrm{Lu}$ and colleagues, ${ }^{2}$ this technique may be an attractive option for those patients large enough to accept a larger conduit. For most children with DORV with noncommitted VSD, the intraventricular conduit may not represent the "light at the end of the tunnel" that we are looking for.

\section{References}

1. Lacour-Gayet F, Haun C, Ntalakoura K, Belli E, Houyel L, Marcsek P, et al Biventricular repair of double outlet right ventricle with non-committed ventricular septal defect (VSD) by VSD rerouting to the pulmonary artery and arterial switch. Eur J Cardiothorac Surg. 2002;21:1042-8.

2. Lu T, Li J, Hu J, Huang C, Tan L, Wu Q, et al. Biventricular repair of double-outlet right ventricle with noncommitted ventricular septal defect using intraventricular conduit. J Thorac Cardiovasc Surg. 2020;159:2397-403.

3. Villemain O, Belli E, Ladouceur M, Houyel L, Jalal Z, Lambert V, et al. Impact of anatomic characteristics and initial biventricular surgical strategy on outcomes in various forms of double-outlet right ventricle. J Thorac Cardiovasc Surg. 2016; 152:698-706.e3.

4. Li S, Ma K, Hu S, Hua Z, Yang K, Yan J, et al. Surgical outcomes of 380 patients with double outlet right ventricle who underwent biventricular repair. J Thorac Cardiovasc Surg. 2014;148:817-24. 